\title{
DIFFERENCES IN COMPETITIVE ABILITY BETWEEN GENOTYPES OF DROSOPHILA
}

\author{
KENNETH MATHER and PATRICIA COOKE \\ Agricultural Research Council Unit of Biometrical Genetics, \\ Deportment of Genetics, University of Birminghom
}

Received 1.i.62

\section{INTRODUCTION}

Not all forces of natural selection spring from the direct competition of individuals. Adjustment to the physical environment obviously need involve nothing more than the greater success of the individual better fitted to meet the demands of that environment. Yet situations must be rare into which some element of competition does not enter. Even those individuals of a species colonising a new environment must meet some sort of competition from other species already present and making similar demands on the outside world; and if the colonisers achieve any success beyond the bare maintenance of their numbers, sooner or later the population must rise to a size when its members become significant features of one another's environment and there sets in the fiercer competition within the species. Competition is not synonymous with natural selection, but competitive ability must be a major component of fitness so that anything we can learn about it will add correspondingly to our understanding of fitness, its nature and its determination.

It could hardly be doubted, and indeed has long been clear, that competitive ability is mediated genically. The changes in the frequencies of inversion sequences in Drosophila pseudo-obscura, which Dobzhansky and his colleagues have observed in their population cages, obviously depend on the genes carried by those sequences. The selective forces at work, though inferred from the determinancy of the changes in sequence frequencies rather than demonstrated by the direct observation of individual behaviour, can hardly have failed to depend on the relative abilities of individuals to survive, mate and lay in competition with one another as well as on differences in fertility and any other character which can be formally separated from competitive ability. In barley, and more recently in rice (Sakai, 196r), direct observation has shown that lines of these inbreeding species must differ in their abilities to compete in mixed stands. It has been shown too (Vetukhiv, 1954, and see Wallace and Vetukhiv, 1955) that in a number of species of Drosophila flies of different genotypes differ in their abilities to survive in crowded conditions. In a number of these experiments flies of a constant genotype recognisable by a mutant marker gene were introduced into each culture to serve 
as a control. They survived less successfully than did their wild-type competitors and so must be judged to have a lower competitive ability, but differences among the wild-type genotypes were inferred entirely from their individual survival percentages. They were not compared in competition with one another, nor even was comparison with the mutant control used as a basis for making indirect comparisons among them.

A number of authors have described experiments in which two or more genotypes are compared in respect of some aspect of fitness by their powers of competition with an extraneous standard genotype of the same species. Knight and Robertson (1957), for example, have clearly demonstrated the effects of inbreeding in Drosophila melanogaster in this way and they refer to the measure they use as a "competitive index". Valuable as comparisons so obtained have proved themselves to be, they are nevertheless indirect in their nature, and subject, therefore, to all the reservations that comparisons made through a third genotype must always entail. More detailed consideration and analysis must be immensely facilitated by direct comparisons between the genotypes whose behaviour is under discussion.

In the present series of experiments an attempt has been made to obtain direct estimates of the relative competitive abilities of flies of related genotypes in Drosophila melanogaster, to measure the selective differentials to which these differences in competitive ability give rise, to take a preliminary look at the inheritance of competitive ability, and to learn a little about its effects on the manifestation of sternopleural chaeta number in mixed populations. An account of the first part of the investigation has already appeared (Mather, I961). In this, the classes of fly taken for test in competition with one another were chosen from an $\mathrm{F}_{2}$ between the Oregon and Samarkand inbred lines by the numbers of sternopleural chaetæ that they displayed, those with 18 chaetæ being described as Low, those with 20 as Mid and those with 22 as High. The progeny of Low and High flies appeared to survive but rarely in competition with those of Mid, and Low showed an advantage, though not so great, in competition with High. There was thus a clear indication of stabilising selection in respect of chaeta number, but the weakness of this early experiment lay in the genotypic variety which must be expected among the flies falling into the phenotypic classes, especially the Mid class taken from near the mean of the $\mathrm{F}_{2}$. The experiments now to be described have therefore been based on competition between genetically defined lines rather than phenotypically distinguished classes.

\section{EXPERIMENTAL TECHNIQUE AND RESULTS}

Four of the eight true breeding lines described by Cooke and Mather (Ig62) were used in the experiments. The eight lines represent the Samarkand inbred line $(S)$ and Birmingham strain of the Oregon inbred line (B), together with six further lines, derived from $\mathrm{S}$ and $\mathrm{B}$ 
and comprising with them all the eight possible true-breeding combinations of the three major chromosomes, each chromosome being taken as a unit. Denoting the Oregon chromosomes by B and their Samarkand homologues by $\mathrm{S}$, and writing the symbols for the chromosomes in the order $\mathrm{X}, \mathrm{II}$, III, the four lines used were:-I-BBB, 2-BBS, 4-SSS, 5-SSB, which keep like X and II together, but provide all combinations of these with the $B$ and $S$ chromosomes III. Nine genotypes are thus provided for investigation by these four lines and their $F_{1} s$ as shown in table $I$.

All cultures were raised in glass vials of diameter I inch and height 3 inches, the food cake being poured to a depth of approximately $\frac{1}{2}$ inch in the bottom. Four females were allowed to lay for $3 \frac{1}{2}$ days in the vial at $25^{\circ} \mathrm{C}$. and $4 \frac{1}{2}$ days at $18^{\circ} \mathrm{C}$., previous experience (Mather, I96I) having indicated that this should lead to a culture sufficiently crowded for the effects of competition to show. In a pure culture all

TABLE I

The nine female genotypes used in the experiment

\begin{tabular}{|c|c|c|c|c|c|c|c|c|}
\hline (B/B & $\begin{array}{r}\mathrm{B} / \mathrm{B}) \\
\text { line } \mathrm{I}\end{array}$ & $\mathrm{B} / \mathrm{B}$ & (B/B & $\begin{array}{l}B / B) \\
I \times 2\end{array}$ & $\mathrm{~B} / \mathrm{S}$ & (B/B & $\begin{array}{r}\mathrm{B} / \mathrm{B}) \\
\text { line } 2\end{array}$ & $\mathbf{S} / \mathbf{S}$ \\
\hline (B/S & $\begin{array}{l}B / S) \\
I \times 5\end{array}$ & $\mathrm{~B} / \mathrm{B}$ & $\begin{array}{r}\text { (B/S } \\
I \times\end{array}$ & $\begin{array}{l}\mathrm{B} / \mathrm{S}) \\
\text { and }\end{array}$ & $\begin{array}{l}\text { B/S } \\
\times 5\end{array}$ & (B/S & $\begin{array}{l}B / S) \\
2 \times 4\end{array}$ & $\mathbf{S} / \mathbf{S}$ \\
\hline$(\mathrm{S} / \mathrm{S}$ & $\begin{array}{c}\mathrm{S} / \mathrm{S}) \\
\text { line } 5\end{array}$ & $\mathrm{~B} / \mathrm{B}$ & $(\mathbf{S} / \mathbf{S}$ & $\begin{array}{l}S / S) \\
4 \times 5\end{array}$ & $\mathrm{~B} / \mathrm{S}$ & $(\mathrm{S} / \mathrm{S}$ & $\begin{array}{c}\text { S/S ) } \\
\text { line } 4\end{array}$ & $\mathrm{~S} / \mathrm{S}$ \\
\hline
\end{tabular}

The numbers of the lines and the crosses giving the genotypes are shown beneath the genotypes. The brackets enclose chromosomes $\mathrm{X}$ and II which were treated as a single joint unit in making up the genotypes.

the females were, of course, of the same genotype, and in a mixed culture two females were used of each of the two genotypes being tested against one another. In the preliminary experiments the females were mated to males of the same genotype for two days or so before being introduced into the vials, but in the main experiment matings were made directly into the culture vials.

In the preliminary experiments the flies were lightly etherised and the males removed, so as to prevent cross-mating, before the females were placed in the culture vials, just as in the earlier experiments described by Mather (I96I). The etherisation tends, however, to check laying and thereby to introduce a further variable into the experiments. The main experiments were therefore carried out with a modified technique. Where a mixed culture was to be raised a plastic slip was introduced into the vial with its base resting against the bottom of the vial, so cutting the food cake into two and with its top against the bung, thus dividing the vial into two chambers. The 
females of one genotype were introduced together with their mates into one chamber, and those of the second genotype into the other, cross-mating thus being prevented. When the parents were removed, so also was the slip and the two pieces of food cake were pushed together if necessary. The females of the two types thus laid on separate areas of the surface of the food cake, but once the slip was removed the larvæ would intermingle and the culture became in effect a single mixed one.

Laying proceeded and the offspring developed at $25^{\circ} \mathrm{C}$. or at $18^{\circ} \mathrm{C}$. according to the experiment. When the offspring had emerged, they were collected and a sample of ro flies of each sex was taken for counting the sternopleural chaetæ. The mean chaeta numbers of males and females thus obtained were taken as characterising the flies in the culture, so allowing by comparison with the means for the pure cultures an estimate to be made of the relative contributions of the two genotypes to the surviving output of a mixed culture.

Where a heterozygous genotype was used, whether in pure culture or mixed, the parents were taken from the appropriate true-breeding lines, so that the cross between them would give in the experimental culture offspring of the heterozygous genotype required. The genotypes recorded as having been used in an experiment thus refer to the competing offspring and not to their parents, who were always from true-breeding lines. The genotypes of table I refer specifically to the female offspring: the $\mathrm{X}$ chromosome of the males would vary in the case of heterozygous genotypes according to the way in which the cross was made. All experiments were, however, carried out with an even number of replicates in half of which the cross was made in one way and in half the other, the mean chaeta numbers then being pooled so as to balance out the effects of the $\mathrm{X}$ chromosomes in the males where this chromosome varied with the direction of the cross. Any general maternal effect would equally be balanced out by this procedure.

\section{(i) ?reliminary experiments}

A number of preliminary observations were made before the main tests began. All were carried out at $25^{\circ} \mathrm{C}$. and with undivided vials, the males being removed runder ether before the females were placed in the vials, as already ncted. These preliminary experiments were intended to be explorator: only, and they do not, therefore, merit detailed description. Their results are summarised in table 2.

The term "Background" refers to the constitution in respect of chromosomes $\mathrm{X}$ and II, High being B/B, Mid B/S and Low S/S for these chromosomes. The comparisons were made in each background between flies differing in respect of chromosome III, High $(\mathrm{H})$ being again B/B, Mid (M) B/S and Low (L) S/S. In only one set of experiments, where the background is described as "Own", did chromosomes $\mathrm{X}$ and II differ between the flies being compared. In this set 
the background was of the same constitution as chromosome III, the $\mathrm{H}$ flies being $\mathrm{B} / \mathrm{B}, \mathrm{B} / \mathrm{B}, \mathrm{B} / \mathrm{B}$, the $\mathrm{M}$ flies $\mathrm{B} / \mathrm{S}, \mathrm{B} / \mathrm{S}, \mathrm{B} / \mathrm{S}$ and the $\mathrm{L}$ flies $\mathrm{S} / \mathrm{S}, \mathrm{S} / \mathrm{S}, \mathrm{S} / \mathrm{S}$. Thus the High background experiment compared the three genotypes in the top row of table I, the Mid background experiment compared those in the middle row of table 1 , the Low background experiment those in the bottom row of table $\mathrm{I}$, and the Own background those in the diagonal from top left to bottom right of table 1 .

Each replicate of each experiment comprised six cultures, three pure $(H, M$ and $L$ ) and three mixed ( $H$ and $M, H$ and $L$, and $L$ and $\mathrm{M}$ ). Taking $\overline{\mathrm{H}}, \overline{\mathrm{M}}, \overrightarrow{\mathrm{L}}, \overline{\mathrm{HM}}, \overline{\mathrm{HL}}$ and $\overline{\mathrm{ML}}$, as the mean chaeta

TABLE 2

Results of preliminary experiments

\begin{tabular}{|c|c|c|c|c|c|}
\hline Background & Mean chaetæ & \multicolumn{4}{|c|}{ Competitive abilities } \\
\hline High & $\begin{array}{ll}\text { H } & 22 \cdot 65 \\
\text { M } & 21 \cdot 30 \\
L & 19.55\end{array}$ & $\begin{array}{l}\text { Males } \\
\text { Females } \\
\text { Joint }\end{array}$ & $\begin{array}{l}L, M \\
L>M \\
L>M\end{array}$ & $\begin{array}{l}L>H \\
L, H \\
L>H\end{array}$ & $\begin{array}{l}\mathrm{M}, \mathrm{H} \\
\mathbf{M}>\mathrm{H} \\
\mathbf{M}>\mathrm{H}\end{array}$ \\
\hline Mid & $\begin{array}{ll}H & 21.43 \\
M & 19.88 \\
L & 18.25\end{array}$ & $\begin{array}{l}\text { Males } \\
\text { Females } \\
\text { Joint }\end{array}$ & $\begin{array}{l}L>M \\
L>M \\
L>M\end{array}$ & $\begin{array}{ll}\mathrm{L}, & \mathbf{H} \\
\mathrm{L}, & \mathbf{H} \\
\mathrm{L}, & \mathbf{H}\end{array}$ & $\begin{array}{ll}\mathrm{M}, & \mathrm{H} \\
\mathrm{M}, & \mathrm{H} \\
\mathrm{M}, & \mathrm{H}\end{array}$ \\
\hline Low & $\begin{array}{ll}\text { H } & 20.73 \\
\text { M } & 19.38 \\
\text { L } & 17.98\end{array}$ & $\begin{array}{l}\text { Males } \\
\text { Females } \\
\text { Joint }\end{array}$ & $\begin{array}{l}\mathrm{L}, \mathrm{M} \\
L>M \\
\mathrm{~L}>\mathrm{M}\end{array}$ & $\begin{array}{l}L>\mathrm{H} \\
L>H \\
L>H\end{array}$ & $\begin{array}{l}\mathrm{H}>\mathrm{M} \\
\mathrm{H}>\mathrm{M} \\
H>M\end{array}$ \\
\hline Own & $\begin{array}{ll}\text { H } & 21.84 \\
M & 19.56 \\
L & 17.69\end{array}$ & $\begin{array}{l}\text { Males } \\
\text { Females } \\
\text { Joint }\end{array}$ & $\begin{array}{l}\mathrm{L}>\mathrm{M} \\
M>L \\
\mathrm{~L}, \quad \mathrm{M}\end{array}$ & $\begin{array}{l}\mathrm{L}, \mathrm{H} \\
\mathrm{L}>\mathrm{H} \\
\mathrm{L}>\mathrm{H}\end{array}$ & $\begin{array}{l}M>H \\
\mathrm{M}>\mathrm{H} \\
M>H\end{array}$ \\
\hline
\end{tabular}

A superiority significant at the 5 per cent. level is shown by italics, the direction being indicated by the inequality sign. An indication of superiority (probability of difference between 50 per cent. and 5 per cent.) is shown by an inequality in roman type. An absence of indication of superiority (probability of difference over 50 per cent.) is indicated by a comma between the symbols for the lines.

numbers from these cultures, $\overline{\mathrm{H}}+\overline{\mathrm{M}}-2 \overline{\mathrm{HM}}, \overrightarrow{\mathrm{M}}+\overrightarrow{\mathrm{L}}-2 \overline{\mathrm{ML}}$ and $\overline{\mathrm{H}}+\overline{\mathrm{L}}-2 \overline{\mathrm{HL}}$ should be $\mathrm{o}$ within the limits of sampling variation if the two genotypes contribute equally to the surviving offspring of the mixed culture. A negative value shows an excessive contribution of the genotype with the higher chaeta number, and hence a higher competitive ability of this genotype (see Mather, 1961). Equally a positive value indicates a higher competitive value of the genotype with the lower chaeta number. The designations High, Mid and Low reflect the relative chaeta numbers of the genotypes as will be seen from the second column of table 2 where the chaeta numbers, averaged over sexes, are shown for each of the genotypes in pure culture in these experiments. 
The High, Mid and Low background experiments were carried out in duplicate and the Own experiment in quadruplicate. Comparisons between chaeta numbers of like standing in the duplicate or quadruplicate cultures affords a measure of error variation, against which the values of $\overline{\mathrm{H}}+\overline{\mathrm{M}}-2 \overline{\mathrm{HM}}$ etc. can be tested for significance. In summarising the results in table 2 the convention has been adopted that where the probability of the values of $\overline{\mathrm{H}}+\overline{\mathrm{M}}-2 \overline{\mathrm{HM}}$ etc. departing from o by error variation alone was greater than 50 per cent. no indication could be obtained of superior competitive ability of either genotype and the outcome is shown in the table with a comma, thus $\mathrm{M}, \mathrm{H}$. Where the probability lay between 50 and 5 per cent. there was an indication, but no significant evidence, of inequality in competitive ability, and the outcome is shown with an inequality sign, thus $\mathrm{H}>\mathrm{M}$, the direction of the sign shows the direction of superiority in competitive ability. With a probability of less than 5 per cent., the difference is significant and the outcome is shown again with an inequality sign but now in italics, thus $H>M$. The comparisons are shown separately for males and females, and also for the pooled sexes. By and large the sexes agree quite satisfactorily in the results they give.

The results suggest several points of interest. The $\mathrm{L}(\mathrm{S} / \mathrm{S})$ combination on chromosome III is generally superior to the $M(B / S)$ and $\mathrm{H}(\mathrm{B} / \mathrm{B})$ combinations on High, Mid and Low backgrounds but the relation of $\mathbf{M}$ and $\mathrm{H}$ especially appears to vary with background. In particular $M$ appears superior to $H$ on the High background, but inferior to it on the Low, the relation being one of indifference on the Mid background. There is thus a suggestion of interaction between the chromosomes in their effects on competitive ability. It was, therefore, decided to carry-out more extensive tests in the form of the main experiments, now to be described. Before turning to these, however, one further point requires notice. In the earlier experiments, based on phenotypic classes rather than genotypes, described by Mather (Ig6I), the M phenotype was superior to both $\mathrm{H}$ and $\mathrm{L}$, albeit $\mathrm{L}$ appeared superior to $\mathrm{H}$. In table 2, on the other hand, L consistently appears superior to $\mathbf{M}$ on High, Mid and Low backgrounds, and on the Low background even $\mathrm{H}$ appears superior to $\mathbf{M}$. These comparisons on uniform backgrounds, are not, however, comparable to Mather's earlier ones, where the flies were taken from the $F_{2}$ of Samarkand $\times$ Oregon, and where all chromosomes would be varying together. It was for this reason that the Own background experiments were carried out, it being thought that $\mathrm{L}$ flies from the $\mathrm{F}_{2}$ would be likely to compare most closely with the $\mathrm{S} / \mathrm{S}, \mathrm{S} / \mathrm{S}, \mathrm{S} / \mathrm{S}$ genotype, $M$ from the $F_{2}$ with $B / S, B / S, B / S$, and $H$ from the $F_{2}$ with $\mathrm{B} / \mathrm{B}, \mathrm{B} / \mathrm{B}, \mathrm{B} / \mathrm{B}$. The results of this experiment as set out in the bottom portion of table 2, show that broadly speaking this expectation is realised. Nevertheless, it is not completely clear as the males still suggest a superiority of $\mathrm{L}$ over $\mathbf{M}$, though the females show a much more decisive superiority of $\mathbf{M}$ over $\mathbf{L}$. Evidently the relations 
of the phenotypic classes of the $\mathrm{F}_{2}$ are not matched completely from among this range of nine genotypes. Nor need this surprise us, since there would be not nine but twenty-seven female genotypic combinations of the three whole chromosomes in the $\mathrm{F}_{2}$, and this variety would be increased still further by recombination arising from crossingover within chromosomes.

\section{(ii) Main experiments}

In the main experiments each of the nine genotypes (or lines, as they will be termed for convenience) was tested in competition with every other using the technique of partitioned vials. There are 36 such competitive pairs with 9 lines, so that a full replicate of the tests included 45 cultures, 9 pure and 36 mixed. The tests were carried out at two temperatures, $25^{\circ} \mathrm{C}$. and $18^{\circ} \mathrm{C}$., and they were quadruplicated at each temperature so giving $45 \times 2 \times 4=360$ cultures in all. Mean chaeta numbers were determined for males and females separately from each culture, and the quadruplication was used to balance out the effects of sex-linkage and maternal influence as described in an earlier section.

In addition to determining the chaeta numbers, the total yield of flies was also found for each culture and the sexes were counted separately for this purpose at $25^{\circ}$ but not at $18^{\circ}$. Analysis of the results for the $25^{\circ}$ cultures showed, however, that there was no detectable variation in sex-ratio beyond that expected from sampling, so the numbers of the two sexes have been pooled for further consideration in the $25^{\circ}$ experiment as well as the $18^{\circ}$.

The mean yield of flies, males and females being taken jointly, is shown for each of the combinations of lines at both temperatures in table 3. Each entry is, of course, the mean of the four replicate cultures. The line means are the mean yields of all nine combinations, eight mixed and one pure, in which that line has taken part. Taking the pooled variation among the quadruplicate cultures of the 45 combinations as the estimate of error, analysis of variance reveals that the arrays differ significantly from one another in their yields of flies at both temperatures, but that no other significant difference is to be found. In particular the average yield of the 36 mixed combinations does not differ significantly from the average of the 9 pure types at either temperature. Thus the nine parent lines must differ in the numbers of their flies that came through under the conditions of these experiments; but there is no evidence of further complication in respect of yield of flies. The line mean yields at the two temperatures are correlated but not very highly so, with $r=0.409$.

The mean numbers of sternopleural chaeta are shown for males and females separately in each of the 45 combinations, at the two temperatures, in table 4. Again each entry is the mean of the four replicate cultures of the combination. No correction has been made 
to the chaeta numbers for the effects of differences in the numbers of flies emerging in the cultures. Mather ( $196 \mathrm{I}$ ) found such a correction to be necessary, but in the present results comparisons among the quadruplicate observations on each combination of lines revealed no indication of a dependence of mean chaeta number on the number of flies emerging. To attempt a correction would thus have been redundant.

TABLE 3

The number's of fies yielded by each line and combination of lines at $25^{\circ}$ and $18^{\circ} \mathrm{C}$.

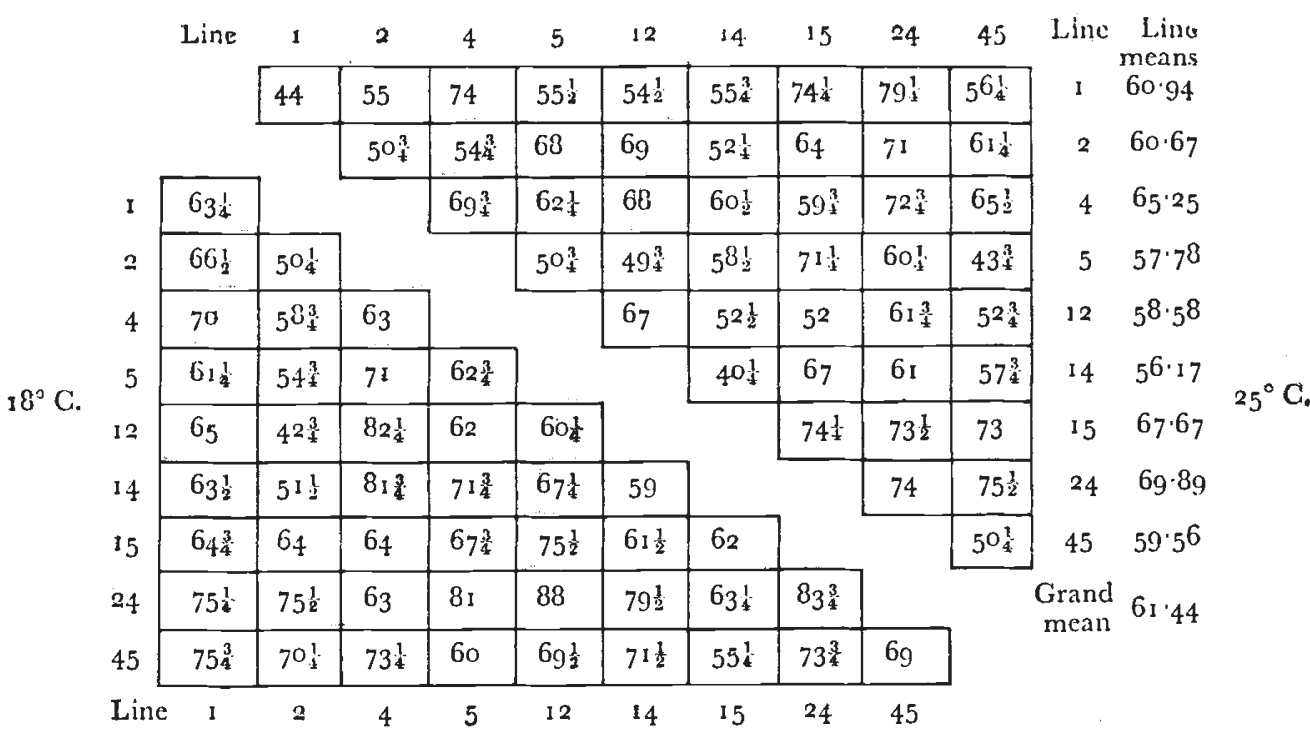

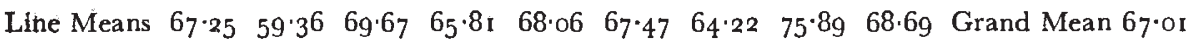

Each entry is the average of four replicate cultures. Each line mean is the mean of the nine combinations in which that line takes part. The grand mean is the mean of the 45 entries in the table and is not the mean of the line means. Note that in this and subsequent tables the $F_{1}$ of the cross between lines 1 and 2 is designated as line 12 , and so on.

The proportionate contributions of the two parental lines to the flies emerging in a mixed culture was estimated from the chaeta numbers. Thus females in line $I$ at $25^{\circ}$ have a mean of $22 \cdot 65$, those of line 2 a mean of 19.95 and those of the mixed culture a mean of 20.38. Now if $p$ and $q(=1-p)$ are respectively the proportions of line 1 and line 2 flies in the mixture, the expectation for the mixed mean must be $22.65 p+19.95 q=19.95+(22.65-19.95) p$. Since the mean of the mixed culture is $20 \cdot 38$, we thus find

and

$$
p=\frac{20 \cdot 3^{8}-19 \cdot 95}{22 \cdot 65-19 \cdot 95}=\frac{0 \cdot 43}{2 \cdot 70}=0 \cdot 1593
$$

$$
q=\frac{22 \cdot 65-20 \cdot 3^{8}}{22 \cdot 65-19 \cdot 95}=\frac{2 \cdot 27}{2 \cdot 70}=0 \cdot 8407
$$


Similarly we find, for example, for males in the $25^{\circ}$ mixed culture of lines 5 and 24 (i.e. the $F_{1} 2 \times 4$ ), where pure line 5 gives a mean of $20 \cdot 73$, pure 24 a mean of $18 \cdot 9^{8}$ and the mixed culture a mean of 19.58 ,

and

$$
p=\frac{19 \cdot 5^{8}-18 \cdot 9^{8}}{20 \cdot 73-18 \cdot 9^{8}}=0 \cdot 34^{29}
$$

$$
q=\frac{20 \cdot 73-19 \cdot 5^{8}}{20 \cdot 73-18 \cdot 9^{8}}=0.6571
$$

Although this calculation has been illustrated using the means of the four replicate cultures of each combination, it was in fact carried out separately for each replicate of the four, the counts being used from the two pure cultures and the mixed culture from within the same replicate. Thus four such estimates became available of the proportionate contributions of the two lines concerned to the flies from each type of mixed culture.

These estimates of the proportionate contributions are obviously

\section{TABLE 4}

Mean numbers of sternopleural chaeta in females (above) and males (below) of the various lines and combinations of lines at $25^{\circ} \mathrm{C}$. and $18^{\circ} \mathrm{C}$.

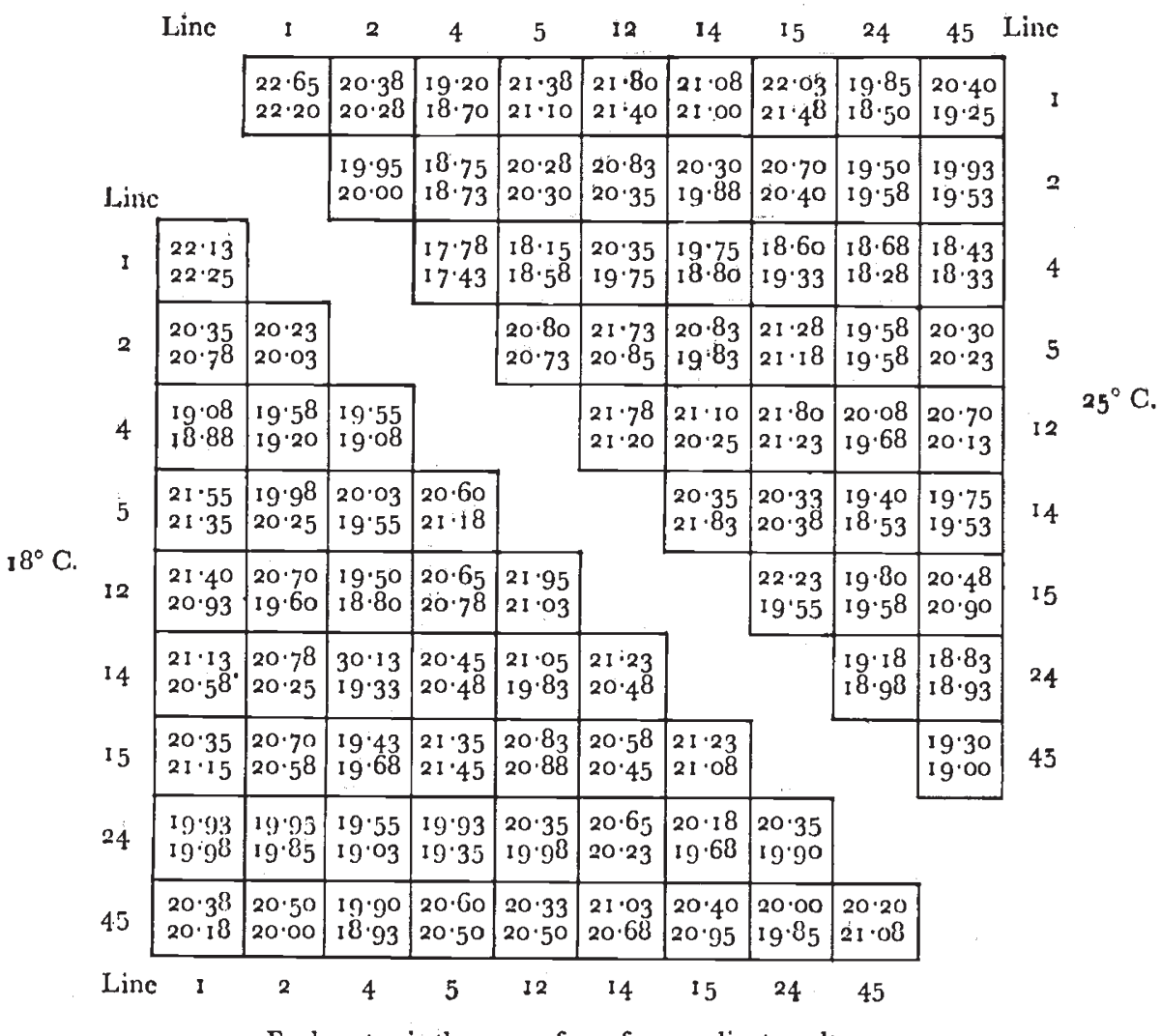


subject to error arising not only from the sampling variation of the proportion itself but also from the variation in sternopleural chaeta which is a commonplace among flies even of a uniform genotype. The greater the difference in chaeta number between the component lines of the mixed culture, the less the disturbance produced in the estimates of the proportionate contributions by the variation of individual chaeta numbers. With small differences between the lines, however, these disturbances can be relatively great and lead even to negative estimates of the contributions. A case in point is offered by the females of the mixed culture of lines 5 and $I_{4}$ at $25^{\circ}$. The pure culture means are $20 \cdot 80$ and 20.35 , that of the mixed culture being 20.83 , leading to the estimates

and

$$
p=\frac{20 \cdot 80-20 \cdot 83}{20 \cdot 80-20 \cdot 35}=-0.0667
$$

$$
q=\frac{20 \cdot 83-20 \cdot 35}{20 \cdot 80-20 \cdot 35}=\mathrm{I} \cdot 0667
$$

Other and more extreme cases can be found from table 4 . It is, of course, obvious that the extreme values possible for $p$ and $q$ must be $o$ and I. Before, however, considering how to deal with these cases we must first turn to consider the metric to be adopted in measuring competitive ability.

\section{3. measurement of relative competitive ability}

(i) The metric

If measurements of relative competitive ability are to be of general use they must clearly allow the behaviour of two lines relative to one another to be predicted from knowledge of the behaviour of each of them with a third line, i.e. the measurements should be such that knowing the differences in relative competitive ability between lines $A$ and $B$, and between $B$ and $C$, the difference between $A$ and $C$ can then be predicted. Furthermore, the simplest relation for prediction is that of additivity so that the difference between $\mathrm{A}$ and $\mathrm{C}$ would be the sum, taking sign into account, of those between $A$ and $B$ and $B$ and C. Simple proportionate contributions to mixed cultures do not satisfy this criterion of additivity any more than do simple recombination percentages in linkage. We need in fact some metric which like cross-over value can be used additively.

Let us consider the simple case of a mixture of two lines contributing equally to the initial population of fertile eggs which then develops under conditions of competition such that there survive only half the individuals to which the eggs could give rise. Let us further suppose that the individuals can be ordered on a scale measuring competitive ability, that on this scale the individuals of each line show a normal distribution, and that although having different means the distributions of the two lines have the same variance (fig. I, lower). Then 
only the individuals in the upper half of the joint distribution will survive and they will be represented by the areas of the two distributions to the right of the dotted vertical line in the figure. The survivors from the line of lower mean will clearly match in frequency those failing to survive from the line of higher mean, and with normal distributions of equal variance the dividing line will be the ordinate through the point of intersection of the curves, as in the figure. The outcome of the mixed culture may thus be represented by the relation of the areas of the higher curve appearing on either side of this ordinate, that area to the right of the ordinate being the proportion of survivors coming from the line of higher mean and that to the left being the proportion coming from the line of lower mean. Now the position of this ordinate in relation to the mean of either distribution can be expressed as a normal deviate. This normal deviate can be ascertained from the proportions of the two lines in the survivors of the mixed culture, and it will be just one half the difference in mean competitive ability between the lines. Furthermore, such normal deviates will provide additive measures of competitive ability, so long, of course. as the competitive powers of the lines depend on the same factors and can be expressed on the same scale.

Now, we obviously cannot know that exactly half the potential individuals of the mixed culture will survive. Where more than 50 per cent. of the potential individuals survive the normal deviate breaks down as a measure of competitive ability, for the value ascertained for it from the proportions of the two lines surviving is no longer related in a utilisable fashion to the difference between the mean of the lines. Where, however, less than 50 per cent. of the potential individuals survive (fig. I, upper), the normal deviate corresponding to the proportion of the mixture continues to be a useful measure of the difference in competitive power. True, it is no longer half the difference between the mean of the lines, as it is with $5^{\circ}$ per cent. survival, but as our colleague, Mr R. Morley Jones, has pointed out to us, for a constant rate of survival less than 50 per cent., the normal deviate derived from the proportion changes almost linearly with the difference between the lines' mean competitive abilities (fig. 2). So, provided the in tensity of competition, and with it the survival rate, is held constant the normal deviate is a satisfactory measure, at least until the survival rate begins to exceed 50 per cent.

\section{(ii) Testing additivity}

Data such as those from the present experiment, where a number of lines were tried in all combinations, clearly afford the means of testing both the differences between the lines in competitive ability and the additivity of the measures obtained in practice on the metric being used. The principles of these tests can be seen from consideration of the simplest case of three lines tested in all combinations. The results of such a test can be set out as in table 5 , in which $a$ is 
the normal deviate (or indeed other similar metric) obtained from the proportion of line 2 recovered in experiment from the combination of this line with line I. Then clearly since there must be a complementary proportion of individuals from line I, this line will show a value of $-a$ in respect of the mixed culture of $I$ and 2. Similarly $b$ in the measure derived from the proportions of line 3 individuals and $-b$ the measure from the proportion of line 2 individuals, observed in the mixed culture of 2 and 3 , with $c$ and $-c$ correspondingly for

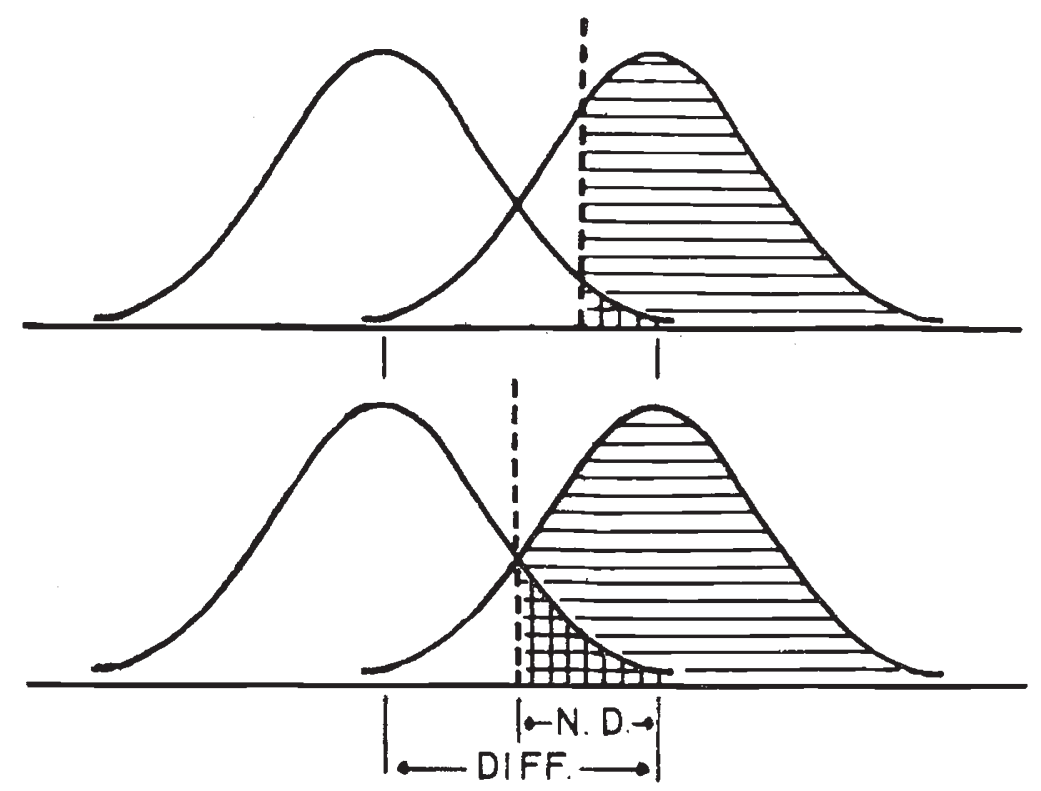

FIG. 1.-The normal deviate as a measure of differences in competitive ability.

The individuals of each line are assumed to fall into a normal distribution in respect of competitive ability (measured along the abscissa), the two lines following distributions with different means but a common variance. With 50 per cent. survival (below) the proportions of the two lines among the survivors are given by the areas of the two curves cut off by the ordinate through their intersection, as indicated by the horizontal hatching (for the line of higher mean) and vertical hatching (for the line of lower mean). This ordinate is equidistant between the two means so that the normal deviate corresponding to the proportions of survivors from the two lines is a direct measure of half the difference in their mean competitive abilities.

This simple relation no longer holds where other than half the individuals survive (above). The normal deviate corresponding to the proportions observed among the survivors, is, however, still almost directly proportional to the difference between the means, provided the fraction of individuals surviving is constant and less than a half (see fig. 2).

the mixed culture of $\mathrm{I}$ and 3 . The value in any given cell of table 5 relates to the proportion of individuals of the line shown at the top of the column when in competition with the line at the left of the row in which it appears. Let the values expected where $a$ and $b$ are observed be $\alpha$ and $\beta$, from which $a$ and $b$ may depart by sampling variation. Then assuming additivity as the null hypothesis, $\alpha+\beta$ will be expected where $c$ is observed. The pure cultures necessarily 
give values of $o$ both for observation and expectation and these are entered along the appropriate diagonal of the table.

It is not difficult to show that the least squares estimates are $\alpha=\frac{1}{3}(2 a-b+c)$ and $\beta=\frac{1}{3}(2 b-a+c)$. Now the mean of the three

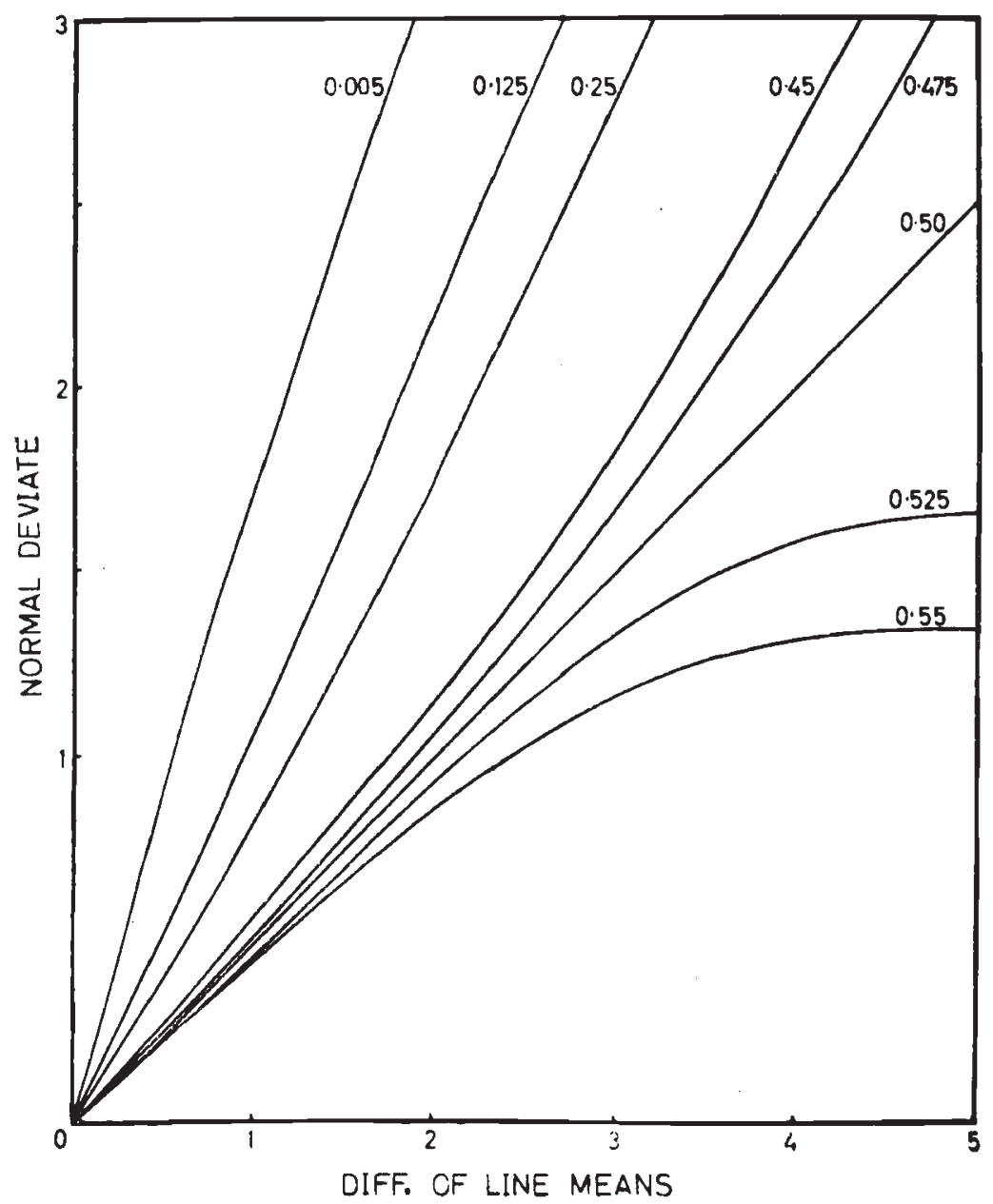

FIG. 2.-The relation between the normal deviates corresponding to proportions observed among the survivors (ordinate) and the difference between the means of the lines in competitive ability (abscissa) for different fractions of survival. The fractions of the individuals surviving are shown against the corresponding lines on the graph. The relation is truly linear only where half the individuals survive, but with less than half surviving the relations are sufficiently near to linearity for the normal deviate to be used in practice as a measure of the difference between the means. With more than half surviving this is no longer true.

entries in the column representing the behaviour of line $\mathrm{I}$ is $\frac{1}{3}(-a-c)$, that for line 2 is $\frac{1}{3}(a-b)$ and that for line 3 is $\frac{1}{3}(b+c)$. Thus the difference between the columns for line 2 and line $I$ is

$$
\frac{1}{3}(a-b)-\frac{1}{3}(-a-c)=\frac{1}{3}(2 a-b+c)=\alpha
$$

and the difference between the means of the columns for line 3 and 
line 2 is $\frac{1}{3}(b+c)-\frac{1}{3}(a-b)=\frac{1}{3}(2 b-a+c)=\beta$. Similarly subtracting the line I mean from that for line 3 gives

$$
\frac{1}{3}(b+c)-\frac{1}{3}(-a-c)=\frac{1}{3}(2 c+b+a)=\alpha+\beta .
$$

The difference in competitive ability between two lines is thus estimated by the difference between the means of the columns representing those two lines.

Although the table contains nine entries only three of these can in fact vary, for the entries along the diagonal must all be o, and given the three entries $(a, b$ and $c)$ to the right of the diagonal, those to the left $(-a,-b,-c)$ must follow. The sum of squares (S.S.) of the table is thus $a^{2}+b^{2}+c^{2}$ for 3 degrees of freedom. If we substitute the values estimated for $\alpha$ and $\beta$, we expect $\frac{1}{3}(2 a-b+c)$ where $a$ is observed, $\frac{1}{3}(2 b-a+c)$ where $b$ is observed and $\frac{1}{3}(2 c+a+b)$ where $c$ is observed. The S.S. remaining after estimating $\alpha$ and $\beta$ is thus

$$
\left[a-\frac{1}{3}(2 a-b+c)\right]^{2}+[b-(2 b-a+c)]^{2}+[c-(2 c+a+b)]^{2}
$$

TABLE 5

\begin{tabular}{|c|c|c|c|}
\hline Line & I & 2 & 3 \\
\hline I & 0 & $\begin{array}{l}a \\
\alpha\end{array}$ & $\begin{array}{c}c \\
\alpha+\beta\end{array}$ \\
\hline 2 & $\begin{array}{l}-a \\
-\alpha\end{array}$ & 0 & $\begin{array}{l}b \\
\beta\end{array}$ \\
\hline 3 & $\begin{array}{c}-c \\
-\alpha-\beta\end{array}$ & $\begin{array}{l}-b \\
-\beta\end{array}$ & 0 \\
\hline Total & $\begin{array}{c}-a-c \\
-2 \alpha-\beta\end{array}$ & $\begin{array}{l}a-b \\
\alpha-\beta\end{array}$ & $\begin{array}{c}b+c \\
\alpha+2 \beta\end{array}$ \\
\hline
\end{tabular}

The case of three lines

and this will correspond to I degree of freedom since the estimation of 2 parameters has used up 2 of the original degrees of freedom. When compared with an appropriate error variance this S.S. provides a test of the adequacy of the parameters to represent the situation. Since estimates were obtained assuming additivity as the null hypothesis, such a test of adequacy is in fact a test of additivity. This indeed becomes obvious when it is realised that

$\left[a-\frac{1}{3}(2 a-b+c)\right]^{2}+\left[b-\frac{1}{3}(2 b-a+c)\right]^{2}+\left[c-\frac{1}{3}(2 c+a+b)\right]^{2}=\frac{1}{3}(a+b-c)^{2}$ which can only exceed the limits of error variation if $c$ fails to equal the sum of $a$ and $b$ within the limits allowed by error.

The remaining S.S., corresponding to 2 degrees of freedom, can be found from the column totals. When squared, summed and divided by 3 , (in accordance with the normal procedure of the analysis of variance), the column totals give

$$
\frac{1}{3}\left[(-a-c)^{2}+(a-b)^{2}+(b+c)^{2}\right]=\frac{1}{3}\left(2 a^{2}+2 b^{2}+2 c^{2}-2 a b+2 a c+2 b c\right) \text {. }
$$

This S.S. is a test of significance of the differences in competitive 
ability, as can be readily seen if it is broken down into two items, each for a single degree of freedom. One of these is found as the S.S. arising from the difference between the column totals of lines I and 3 and is

$$
\frac{1}{6}\left(a^{2}+b^{2}+4 c^{2}+2 a b+4 a c+4 b c\right)=\frac{1}{6}(a+b+2 c)^{2}=\frac{1}{6}(3 \alpha+3 \beta)^{2} .
$$

The other compares twice the line 2 total with the sum of the line I and line 3 totals, or either the line 2 total or the sum of lines $I$ and 3 totals with an expectation of zero, whichever way we choose to look at it. It is $\frac{1}{2}[a-2 a b+b]^{2}=\frac{1}{2}(a-b)^{2}=\frac{1}{2}(\alpha-\beta)^{2}$. So one of the degrees of freedom provides a test of the sum of $\alpha$ and $\beta$ as estimated and the other a test of their difference. There is, of course, no reason why $\alpha$ should equal $\beta$ so that little interest attaches to this last S.S. in practice, and indeed there may be little point in partitioning the marginal S.S. When carried out completely, however, the analysis of variance becomes

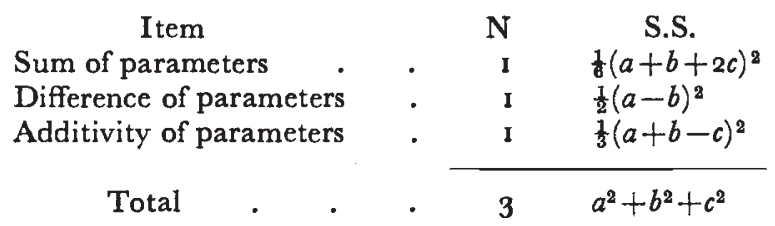

With the principles of the analysis thus established it is readily extended to the more complex case of nine lines tested in all combinations, as in our experiments, to which we now return.

\section{THE STATISTICAL ANALYSIS}

The first task is to convert the proportions of flies from the various mixed cultures, as estimated from the chaeta numbers, jnto normal deviates. In point of fact, however, it is more convenient to convert them into probits which are no more than normal deviates to which 5 has been added so eliminating negative values and facilitating subsequent calculations. Probits have been fully tabulated against the proportions to which they correspond by Fisher and Yates (r 957). Two points must be made about the probit values. First, like the proportions from which they are derived, the sampling variances to which probits are subject vary with the values of the probits themselves. Each probit should therefore be given an appropriate weight in any subsequent analysis (see for example, Finney, I952). This, however, has not been done in the present case, partly to simplify the analysis and partly because the probits as we find them are subject to a still further sampling error springing from the innate variation in chaeta number. Reliance was placed therefore on an empirical estimate of error based on the differences observed among the probits obtained from the quadruplicate observations.

Secondly, some of the proportions found from comparison of the chaeta numbers are I oo and o per cent., which correspond respectively 
to probits of $\infty$ and $-\infty$. As estimated, other proportions even go beyond this range, and can have no probits to correspond. In normal probit analysis special methods are used to cope with the cases of Ioo and o per cent. proportions, but the application of these in the present instance is not obvious, and in any case they cannot take care of the negative values and those exceeding roo per cent. which our

TABLE 6

Mean probits, and relative competitive abilities derived from them, for females (above) and males (below) at $25^{\circ} \mathrm{C}$. and $18^{\circ} \mathrm{C}$.

$25^{\circ} \mathrm{C}$.

\begin{tabular}{|c|c|c|c|c|c|c|c|c|c|}
\hline Line & I & 2 & 4 & 5 & 12 & I 4 & I 5 & 24 & 45 \\
\hline I & 5 & $\begin{array}{l}6 \cdot 0945 \\
6 \cdot 1057\end{array}$ & $\begin{array}{l}5.6179 \\
5.7189\end{array}$ & $\begin{array}{l}5 \cdot 5700 \\
6 \cdot 18_{31}\end{array}$ & $\begin{array}{l}5 \cdot 8564 \\
5 \cdot 953^{8}\end{array}$ & $\begin{array}{l}5.4421 \\
5.3214\end{array}$ & $\begin{array}{l}5 \cdot 9800 \\
4 \cdot 2156\end{array}$ & $\begin{array}{l}6 \cdot 1329 \\
6 \cdot 7457\end{array}$ & $\begin{array}{l}5.4736 \\
6.5387\end{array}$ \\
\hline 2 & $\begin{array}{l}3.9055 \\
3.8943\end{array}$ & 5 & $\begin{array}{l}5 \cdot 2488 \\
4 \cdot 805^{8}\end{array}$ & $\begin{array}{l}3.8726 \\
5 \cdot 0000\end{array}$ & $\begin{array}{l}4 \cdot 7072 \\
4 \cdot 5733\end{array}$ & $\begin{array}{l}4 \cdot 5100 \\
3 \cdot 4076\end{array}$ & $\begin{array}{l}4.5101 \\
5.0234\end{array}$ & $\begin{array}{l}4.3051 \\
4.8007\end{array}$ & $\begin{array}{l}5.2578 \\
4.9052\end{array}$ \\
\hline 4 & $\begin{array}{l}4 \cdot 382 \mathrm{I} \\
4 \cdot 28 \mathrm{II}\end{array}$ & $\begin{array}{l}4 \cdot 75^{12} \\
5 \cdot 194^{2}\end{array}$ & 5 & $\begin{array}{l}3 \cdot 7211 \\
4 \cdot 5674\end{array}$ & $\begin{array}{l}5 \cdot 3708 \\
5 \cdot 4753\end{array}$ & $\begin{array}{l}5 \cdot 4403 \\
4 \cdot 4922\end{array}$ & $\begin{array}{l}3.9218 \\
6 \cdot 2070\end{array}$ & $\begin{array}{l}5.5208 \\
4.9717\end{array}$ & $\begin{array}{l}4 \cdot 8659 \\
5 \cdot 2455\end{array}$ \\
\hline 5 & $\begin{array}{l}4.4300 \\
3.8169\end{array}$ & $\begin{array}{l}6 \cdot 1274 \\
5 \cdot 0000\end{array}$ & $\begin{array}{l}6 \cdot 2789 \\
5 \cdot 4326\end{array}$ & 5 & $\begin{array}{l}6 \cdot 1327 \\
4 \cdot 2304\end{array}$ & $\begin{array}{l}3.9567 \\
3.0400\end{array}$ & $\begin{array}{l}4 \cdot 6476 \\
3 \cdot 0400\end{array}$ & $\begin{array}{l}5 \cdot 9202 \\
5 \cdot 0799\end{array}$ & $\begin{array}{l}4.4156 \\
4.1506\end{array}$ \\
\hline 12 & $\begin{array}{l}4 \cdot 1436 \\
4 \cdot 0462\end{array}$ & $\begin{array}{l}5.2928 \\
5.4267\end{array}$ & $\begin{array}{l}4 \cdot 6292 \\
4 \cdot 5247\end{array}$ & $\begin{array}{l}3 \cdot 8673 \\
5 \cdot 7696\end{array}$ & 5 & $\begin{array}{l}5.1226 \\
3.475^{8}\end{array}$ & $\begin{array}{l}4.055^{\circ} \\
3 \cdot 2516\end{array}$ & $\begin{array}{l}5.4036 \\
5.5650\end{array}$ & $\begin{array}{l}4.7609 \\
5.06 \mathrm{I} 6\end{array}$ \\
\hline 14 & $\begin{array}{l}4.5579 \\
4.6786\end{array}$ & $\begin{array}{l}5 \cdot 4900 \\
6 \cdot 59^{24}\end{array}$ & $\begin{array}{l}4.5597 \\
5.5078\end{array}$ & $\begin{array}{l}6 \cdot 0433 \\
6 \cdot 9600\end{array}$ & $\begin{array}{l}4 \cdot 8774 \\
6 \cdot 5^{2} 4^{2}\end{array}$ & 5 & $\begin{array}{l}4.5646 \\
5 \cdot 3577\end{array}$ & $\begin{array}{l}4.7054 \\
6.9167\end{array}$ & $\begin{array}{l}5 \cdot 6769 \\
6 \cdot 045^{8}\end{array}$ \\
\hline I5 & $\begin{array}{l}4 \cdot 0200 \\
5 \cdot 7844\end{array}$ & $\begin{array}{l}5 \cdot 4899 \\
4 \cdot 9766\end{array}$ & $\begin{array}{l}6 \cdot 0782 \\
3 \cdot 793^{\circ}\end{array}$ & $\begin{array}{l}5 \cdot 35^{24} \\
6 \cdot 9600\end{array}$ & $\begin{array}{l}5.945^{\circ} \\
6.7484\end{array}$ & $\begin{array}{l}5.4354 \\
4.6423\end{array}$ & 5 & $\begin{array}{l}6 \cdot 086 I \\
5 \cdot 15^{62}\end{array}$ & $\begin{array}{l}5.3137 \\
4.0200\end{array}$ \\
\hline 24 & $\begin{array}{l}3 \cdot 867 \mathrm{I} \\
3 \cdot 2543\end{array}$ & $\begin{array}{l}5 \cdot 6949 \\
5 \cdot 1993\end{array}$ & $\begin{array}{l}4.4792 \\
5.0283\end{array}$ & $\begin{array}{l}4 \cdot 0798 \\
4 \cdot 9201\end{array}$ & $\begin{array}{l}4.5964 \\
4 \cdot 4350\end{array}$ & $\begin{array}{l}5 \cdot 2946 \\
3 \cdot 0833\end{array}$ & $\begin{array}{l}3.9139 \\
4.843^{8}\end{array}$ & 5 & $\begin{array}{l}3.0400 \\
4.9268\end{array}$ \\
\hline 45 & $\begin{array}{l}4 \cdot 5264 \\
3 \cdot 4613\end{array}$ & $\begin{array}{l}4 \cdot 74^{22} \\
5 \cdot 094^{8}\end{array}$ & $\begin{array}{l}5 \cdot 1341 \\
4 \cdot 7545\end{array}$ & $\begin{array}{l}5.5844 \\
5.8494\end{array}$ & $\begin{array}{l}5 \cdot 2391 \\
4 \cdot 93^{8} 4\end{array}$ & $\begin{array}{l}4 \cdot 3231 \\
3 \cdot 954^{2}\end{array}$ & $\begin{array}{l}4 \cdot 6863 \\
5 \cdot 9800\end{array}$ & \begin{tabular}{|l|}
$6 \cdot 9600$ \\
$5 \cdot 073^{2}$
\end{tabular} & 5 \\
\hline $\begin{array}{l}\text { Mean } \\
\text { probit }\end{array}$ & $\begin{array}{l}4 \cdot 3147 \\
4 \cdot 2463\end{array}$ & $\begin{array}{l}5 \cdot 4092 \\
5 \cdot 3989\end{array}$ & $\begin{array}{l}5 \cdot 2251 \\
4.9517\end{array}$ & $\begin{array}{l}4 \cdot 7879 \\
5 \cdot 6900\end{array}$ & $\begin{array}{l}5 \cdot 3028 \\
5 \cdot 3199\end{array}$ & $\begin{array}{l}4 \cdot 9472 \\
4 \cdot 0463\end{array}$ & $\begin{array}{l}4 \cdot 5866 \\
4 \cdot 7688\end{array}$ & $\begin{array}{l}5.5593 \\
5.4788\end{array}$ & $\begin{array}{l}4 \cdot 8672 \\
5.0994\end{array}$ \\
\hline $\begin{array}{c}\text { Relative } \\
\text { competitive } \\
\text { value }\end{array}$ & $\begin{array}{l}-0.6853 \\
-0.7537\end{array}$ & $\begin{array}{l}0.4092 \\
0.3989\end{array}$ & $\begin{array}{r}0.2251 \\
-0.0483\end{array}$ & $\begin{array}{r}-0.2121 \\
0.6900\end{array}$ & $\begin{array}{l}0.3028 \\
0.3199\end{array}$ & $\begin{array}{l}-0.0528 \\
-0.9537\end{array}$ & $\begin{array}{l}-0.4134 \\
-0.2312\end{array}$ & $\begin{array}{l}0.5593 \\
0.4788\end{array}$ & $\begin{array}{r}-0.1328 \\
0.0994\end{array}$ \\
\hline
\end{tabular}

data necessarily yield. It was decided, therefore, to adopt the simple, if crude and somewhat arbitrary, procedure of counting all proportions in excess of 97.5 per cent. as 97.5 per cent. and all below 2.5 per cent. as 2.5 per cent.

The mean probits for all combinations are shown for males and females separately at the two temperatures in table 6. Each of the entries in the table is the means of four probit values, found for the four replicate observations of that sex at that temperature in that 
combination. Each of the quadruplicate probits was found separately from the proportion obtained from the chaeta numbers in that particular replicate of the experiment, as already explained. Although the means alone are shown in the table, the sets of four replicate probits were used to provide the estimates of error variation. Since the mean of a number of probits is not the probit of the mean of the proportions from which they are derived, the entries in table 6 do not correspond exactly with the probits derivable from the mean proportions calculated from the chaeta counts of table 4 . The nine pure cultures along the diagonals of table 6 necessarily take probit

TABLE 6 (contd.)

${ }_{1} 8^{\circ} \mathrm{C}$.

\begin{tabular}{|c|c|c|c|c|c|c|c|c|c|}
\hline Line & I & 2 & 4 & 5 & I 2 & I 4 & I 5 & 24 & 45 \\
\hline I & 5 & $\begin{array}{l}6 \cdot 35^{2} 8 \\
5 \cdot 235^{2}\end{array}$ & $\begin{array}{l}6 \cdot 9600 \\
6 \cdot 9355\end{array}$ & $\begin{array}{l}4 \cdot 6007 \\
6 \cdot 0143\end{array}$ & $\begin{array}{l}4 \cdot 8 \text { I } 52 \\
6 \cdot 1134\end{array}$ & $\begin{array}{l}6 \cdot 5573 \\
6 \cdot 0494\end{array}$ & $\begin{array}{l}6 \cdot 725^{1} \\
6 \cdot 33^{8} 9\end{array}$ & $\begin{array}{l}6 \cdot 8925 \\
6 \cdot 3067\end{array}$ & $\begin{array}{l}6 \cdot 1371 \\
6 \cdot 9600\end{array}$ \\
\hline 2 & $\begin{array}{l}3 \cdot 6472 \\
4 \cdot 7648\end{array}$ & 5 & $\begin{array}{l}6 \cdot 2469 \\
5 \cdot 9^{2} 45\end{array}$ & $\begin{array}{l}4 \cdot 8539 \\
4 \cdot 6301\end{array}$ & $\begin{array}{l}4 \cdot 18_{35} \\
3 \cdot 0400\end{array}$ & $\begin{array}{l}5 \cdot 2148 \\
5 \cdot 1077\end{array}$ & $\begin{array}{l}4 \cdot 7096 \\
5 \cdot 7926\end{array}$ & $\begin{array}{l}5 \cdot 9800 \\
3 \cdot 85 \text { I } 5\end{array}$ & $\begin{array}{l}5.5628 \\
3.8072\end{array}$ \\
\hline 4 & $\begin{array}{l}3.0400 \\
3.0645\end{array}$ & $\begin{array}{l}3 \cdot 753^{1} \\
4 \cdot 0755\end{array}$ & 5 & $\begin{array}{l}4 \cdot 1301 \\
4 \cdot 2594\end{array}$ & $\begin{array}{l}3.454 \mathrm{I} \\
4 \cdot 4667\end{array}$ & $\begin{array}{l}4 \cdot 94^{21} \\
4 \cdot 5005\end{array}$ & $\begin{array}{l}3 \cdot 453^{2} \\
4 \cdot 4^{8} 47\end{array}$ & $\begin{array}{l}3 \cdot 9511 \\
4 \cdot 4228\end{array}$ & $\begin{array}{l}4 \cdot 9788 \\
3 \cdot 3788\end{array}$ \\
\hline 5 & $\begin{array}{l}5.3993 \\
3.9857\end{array}$ & $\begin{array}{l}5 \cdot 14^{6} \mathrm{I} \\
5 \cdot 3^{6} 99\end{array}$ & $\begin{array}{l}5 \cdot 8699 \\
5 \cdot 7406\end{array}$ & 5 & $\begin{array}{l}3 \cdot 8726 \\
5 \cdot 9800\end{array}$ & $\begin{array}{l}4 \cdot 2996 \\
5 \cdot 725^{8}\end{array}$ & $\begin{array}{l}6 \cdot 7370 \\
5.4900\end{array}$ & $\begin{array}{l}5 \cdot 75^{68} \\
4 \cdot 705^{8}\end{array}$ & $\begin{array}{l}5.2350 \\
5.9800\end{array}$ \\
\hline I 2 & $\begin{array}{l}5 \cdot 1848 \\
3 \cdot 8866\end{array}$ & $\begin{array}{l}5 \cdot 8165 \\
6 \cdot 9600\end{array}$ & $\begin{array}{l}6 \cdot 5459 \\
5 \cdot 5333\end{array}$ & $\begin{array}{l}6 \cdot 1274 \\
4 \cdot 0200\end{array}$ & 5 & $\begin{array}{l}5.7133 \\
5.9800\end{array}$ & $\begin{array}{l}6 \cdot 63^{8} 7 \\
4 \cdot 0200\end{array}$ & $\begin{array}{l}6 \cdot 2919 \\
4 \cdot 5790\end{array}$ & $\begin{array}{l}5.9864 \\
4.5100\end{array}$ \\
\hline 14 & $\begin{array}{l}3.44^{27} \\
3.9506\end{array}$ & $\begin{array}{l}4 \cdot 7^{8} 5^{2} \\
4 \cdot 89^{2} 3\end{array}$ & $\begin{array}{l}5.0579 \\
5.4995\end{array}$ & $\begin{array}{l}5 \cdot 7004 \\
4 \cdot 274^{2}\end{array}$ & $\begin{array}{l}4^{: 2867} \\
4^{\circ} \cdot 0200\end{array}$ & 5 & $\begin{array}{l}5 \cdot 9800 \\
5 \cdot 9800\end{array}$ & $\begin{array}{l}5 \cdot 135^{2} \\
5 \cdot 4344\end{array}$ & $\begin{array}{l}4 \cdot 1734 \\
4 \cdot 3235\end{array}$ \\
\hline I 5 & $\begin{array}{l}3.2749 \\
3.66 \mathrm{II}\end{array}$ & $\begin{array}{l}5 \cdot 2904 \\
4 \cdot 2074\end{array}$ & $\begin{array}{l}6 \cdot 5468 \\
5 \cdot 5 \text { I } 53\end{array}$ & $\begin{array}{l}3 \cdot 2630 \\
4 \cdot 5100\end{array}$ & $\begin{array}{l}3 \cdot 361_{13} \\
5 \cdot 9800\end{array}$ & $\begin{array}{l}4^{\circ} \cdot 0200 \\
4^{\circ} 0200\end{array}$ & 5 & $\begin{array}{l}6 \cdot 1056 \\
4 \cdot 6175\end{array}$ & $\begin{array}{l}5 \cdot 8104 \\
4 \cdot 7343\end{array}$ \\
\hline 24 & $\begin{array}{l}3 \cdot 1075 \\
3 \cdot 6933\end{array}$ & $\begin{array}{l}4 \cdot 0200 \\
6 \cdot 14^{85}\end{array}$ & $\begin{array}{l}6 \cdot 04^{89} \\
5 \cdot 577^{2}\end{array}$ & $\begin{array}{l}4 \cdot 243^{2} \\
5 \cdot 294^{2}\end{array}$ & $\begin{array}{l}3 \cdot 708_{1} \\
5 \cdot 4210\end{array}$ & $\begin{array}{l}4 \cdot 864^{8} \\
4 \cdot 565^{6}\end{array}$ & $\begin{array}{l}3 \cdot 8944 \\
5 \cdot 3^{825}\end{array}$ & 5 & $\begin{array}{l}5.4900 \\
4.6576\end{array}$ \\
\hline 45 & $\begin{array}{l}3.8629 \\
3.0400\end{array}$ & $\begin{array}{l}4 \cdot 4372 \\
6 \cdot 1928\end{array}$ & $\begin{array}{l}5.0212 \\
6.6212\end{array}$ & $\begin{array}{l}4 \cdot 7650 \\
4 \cdot 0200\end{array}$ & $\begin{array}{l}4^{\circ} .13^{6} \\
5.4900\end{array}$ & $\begin{array}{l}5 \cdot 8266 \\
5 \cdot 6765\end{array}$ & $\begin{array}{l}4 \cdot 1896 \\
5 \cdot 2657\end{array}$ & $\begin{array}{l}4 \cdot 5100 \\
5 \cdot 3424\end{array}$ & 5 \\
\hline $\begin{array}{l}\text { Mean } \\
\text { probit }\end{array}$ & $\begin{array}{l}3.9955 \\
3.8941\end{array}$ & $\begin{array}{l}4 \cdot 9557 \\
5 \cdot 3424\end{array}$ & $\begin{array}{l}5.9219 \\
5.8163\end{array}$ & $\begin{array}{l}4 \cdot 7426 \\
4 \cdot 6691\end{array}$ & $\begin{array}{l}4^{\circ} .0772 \\
5^{\cdot} 0568\end{array}$ & $\begin{array}{l}5 \cdot 159^{8} \\
5 \cdot 1806\end{array}$ & $\begin{array}{l}5 \cdot 25^{86} \\
5 \cdot 3060\end{array}$ & $\begin{array}{l}5 \cdot 5137 \\
4.9178\end{array}$ & $\begin{array}{l}5 \cdot 3749 \\
4 \cdot 8168\end{array}$ \\
\hline $\begin{array}{c}\text { Relative } \\
\text { competitive } \\
\text { value }\end{array}$ & $\begin{array}{l}-1 \cdot 0045 \\
-I \cdot 1059\end{array}$ & $\begin{array}{r}-0.0443 \\
0.3424\end{array}$ & $\begin{array}{l}0.9219 \\
0.8163\end{array}$ & $\begin{array}{l}-0.2574 \\
-0.3309\end{array}$ & $\begin{array}{r}-0.9228 \\
0.0568\end{array}$ & $\begin{array}{l}0 \cdot 159^{8} \\
0 \cdot 1806\end{array}$ & $\begin{array}{l}0.2586 \\
0.3060\end{array}$ & $\begin{array}{r}0.5137 \\
-0.0822\end{array}$ & $\begin{array}{r}0.3749 \\
-0.183^{2}\end{array}$ \\
\hline
\end{tabular}

values of 5 corresponding to the normal deviate of o along the diagonal of table 5 .

The mean probits are shown at the foot of each column of the table, and these are converted into the relative competitive values, expressed in terms of normal deviates, by subtracting 5. These estimates of the relative competitive values assume additivity of the differences in competitive ability among the lines. They can be used to find the probit values expected for each cell of the table assuming 
additivity. Taking, for example, the females from lines $I$ and 4 at $25^{\circ} \mathrm{C}$., the relative competitive value for line 4 exceeds that for line $\mathrm{I}$ by $0.225 \mathrm{I}-(-0.6853)=0.9 \mathrm{I} 04$ so that we should expect a probit value of $5+0.9104$ for the line 4 contribution to the mixed culture of $I$ and 4 and one of $5-0.9104$ for the contribution for line $I$. The mean probits observed were 5.6179 for line 4 and correspondingly 4.382 I for line I. The contribution of this combination to the S.S. for additivity is thus $(5.6179-5.9104)^{2}=(4.3821-4.0896)^{2}$. The two cells of the table must obviously yield the same value for the square of the difference between the probits expected and observed, and only one of them is in fact to be counted in when finding the additivity S.S., as we saw in the previous section. There will thus be 36 comparisons contributing in this way to the additivity S.S., one for each of the mixed combinations of the table, but 8 degrees of freedom have been used up by the 8 parameters whose elimination is implicit in the use of the nine column means for formulating the expected values. Thus the additivity S.S. corresponds to $36-8=28$ degrees of freedom.

The S.S. affording a test of the significance of the relative competitive values (which should, of course, all be $o$ in the absence of differences among the lines) is found from the column totals. The squared column sums will be divided by 9 since each of them is the sum of 9 values, and the probit totals may be used for this calculation if a correction is subtracted to allow for the 5 by which the probit exceeds the normal deviate to which it corresponds. In accordance with the normal practice this correction is found as $405^{2} / 8 \mathrm{I}$ since there are $8 \mathrm{I}$ cells in the table giving a grand total of 405 . The S.S. so obtained corresponds to the 8 degrees of freedom among the nine column totals. It could be sub-divided further by analogy with the simple case considered in the previous section, but little is to be gained by such a partition and it is not presented here.

The total S.S. with which the sums of the S.S.s obtained for additivity and from the column totals must agree is found by squaring and summing the 36 probits for the 36 mixed combinations recorded in the table. This S.S. will correspond to 36 degrees of freedom, 28 of which have been allocated to the test of additivity and 8 to the test of the relative competitive values.

The analyses of variance for the separate sexes at both temperatures are shown in table 7. Only the items for additivity and differences in competitive ability are set out, the totals being omitted as redundant. The requirement that the total S.S., obtained independently as described above, tallied with the sum of the two items recorded was satisfied in all four cases. Only the item for error remains for explanation. This was obtained from the S.S.'s. among the replicate observations for each mixed combination. Four probits were obtained from each mixed combination for each sex at each temperature. Thus each mixed combination contributes a S.S. for 3 degrees of freedom relating to differences among the quadruplicate probits. Since there 
are 36 such combinations pooling will give a S.S. for $36 \times 3=108$ degrees of freedom, and such a measure of error variation is obtainable separately for the two sexes at both temperatures. Since, however, the analysis of variance outlined above was carried out on the mean probits for the various combinations the error mean square, found as just described, must be divided by 4 to make it relevant. The values so obtained are those given on table 7 . The replicate probits used in calculating this error mean square were those obtained after reducing to 97.5 all percentages exceeding this value and raising to 2.5 all percentages falling short of it. The mean square will thus be an underestimate of the true error variance.

The results of the analysis are nevertheless clear on both the points at issue. First, none of the additivity mean squares approaches significance, and this despite the underestimation of the error variance. Thus from neither sex at neither temperature is there any evidence

TABLE 7

Analysis of variance of probits

\begin{tabular}{|c|c|c|c|c|c|c|}
\hline \multirow{2}{*}{ Item } & \multirow{2}{*}{ D.f. } & \multicolumn{4}{|c|}{ Mean squares } & \multirow{2}{*}{ Probability } \\
\hline & & \multicolumn{2}{|c|}{ Females-2 $5^{\circ}$ - Males } & \multicolumn{2}{|c|}{ Females-1 $8^{\circ}-$ Males } & \\
\hline $\begin{array}{l}\text { Differences in com- } \\
\text { petitive ability }\end{array}$ & 8 & I 495 & $2 \cdot 824$ & $3 \cdot 685$ & $2 \cdot 572$ & all $<0.00$ I \\
\hline $\begin{array}{l}\text { Additivity of com- } \\
\text { petitive value }\end{array}$ & 28 & 0.353 & 0.471 & $0 \cdot 428$ & $0.4^{8} 3$ & all $0.5-0.2$ \\
\hline Error. . & 108 & 0.298 & 0.389 & 0.412 & 0.476 & $\ldots$ \\
\hline
\end{tabular}

of the metric used for measuring competitive ability departing from additivity. We should note that this is a test only of the adequacy of the metric for representing the character in relation to comparisons between the lines. It is in no way comparable to the scaling tests of Mather (1949) which test the metric in relation to additivity of gene effects: indeed, although true breeding lines and their $\mathrm{F}_{1} \mathrm{~s}$ were used in the experiments, no genetical relationships of the kind needed for such scaling tests were brought into the analysis. Satisfaction of the present criterion of additivity is therefore no guarantee that interactions will not be found at the level of gene action, and indeed there are indications of such interactions as we shall see in the next section.

Secondly, all the mean squares for differences in competitive ability are highly. significant, and indeed the variance ratios are so great that unless the underestimation has reduced the error variance to but a small fraction of its true value their significance cannot be in doubt. Such a gross effect of underestimation is most improbable. There is thus good evidence that the lines do differ in the proportions 
they contribute to the mixed cultures, that is that they differ in competitive ability as we have defined it.

One point requires clearing up. As we have seen, the lines also differ in the average numbers of offspring they yield under the conditions of the experiment. The question arises, therefore, of whether this could account for the differences in their contributions to the mixed cultures. It does not seem likely that the differences could arise in this way, as at $25^{\circ} \mathrm{C}$. for example the biggest difference in average yield of flies (table 3 ) is only $69 \cdot 89-56 \cdot 17$, which would account for proportions of 55.4 and 44.6 per cent. in a mixed culture. The proportions observed depart much more widely from equality. Two tests have, however, been carried out to investigate the possibility further. First, an analysis was made of the regression of competitive ability on mean yield of offspring. In neither sex at neither temperature was there any good evidence of a relation between the two. Secondly and more important, Dr J. S. Gale has calculated the chaeta numbers expected in the males of the mixed cultures at $25^{\circ}$ if the departures from equal contributions to them depended solely on the differences in yields of offspring among the parental lines. The differences between the chaeta numbers observed and those expected is very highly significant $\left(\chi_{[36]}^{2}=133.7\right.$ with $\mathrm{P}$ extremely small). Thus the differences among the lines in competitive ability cannot be ascribed to the differences in their output of offspring. This test is somewhat laborious and its result so clear that it was not carried out on the other sets of data.

Although differences in competitive ability are thus clear in all four sets of data, the intensity of the effect appears not to be constant. The range between the lowest and the highest relative competitive abilities observed among the nine lines in females at $25^{\circ} \mathrm{C}$. is $\mathrm{I} \cdot 24$, in males at $25^{\circ} \mathrm{C}$. $\mathrm{I} \cdot 64$, in females at $18^{\circ} \mathrm{C}$. 1.93 and in males at $18^{\circ} \mathrm{C}$. $\mathrm{I} \cdot 9^{2}$. The greatest effects were thus seen at $18^{\circ} \mathrm{C}$., at which the yields of offspring were slightly higher than at $25^{\circ} \mathrm{C}$. (table 3 ). It would thus appear unlikely that the greater differences in relative competitive ability spring from lower rates of recovery of offspring. Rather it would suggest that there is a difference in the nature of the conditions of competition in the environments produced at the two temperatures.

It is thus of interest to see whether the lines behave the same in relation to one another at the two temperatures when allowance has been made for the overall difference in range of the values obtained for relative competitive ability. Table 8 presents the relative competitive abilities of the lines at the two temperatures after standardisation by dividing the values as they appear at the foot of table 6 by the appropriate range. Thus line I females at $25^{\circ} \mathrm{C}$. have a value of $-0 \cdot 6853$. The overall range is $I \cdot 244^{6}$ so that the standardised value becomes $-\frac{0.6853}{1 \cdot 2446}=-0.5506$ as appears in table 8 . The 
sum of all the values in one row of table 8 is still of course o just as it is at table 6. The S.S. of differences in one row of the table thus corresponds to 8 degrees of freedom and the S.S.'s pooled over all four rows to 32 degrees of freedom. This total S.S. can be partitioned into an item for the gross differences among the lines when summed over sexes and temperatures, an item for the interaction of these line differences with temperature, an item for the interaction of lines and sexes, and finally an item for the double interaction of lines, temperatures and sexes. The analysis of variance is set out in table 9, which also includes an estimate of the basic error springing from the error terms of table 7 . These four error terms of table 7 were first divided by the squares of the ranges to adjust for the standardisation of the relative competitive values, the average taken of the four mean squares

TABLE 8

Standardised relative competitive abilities for the nine lines

\begin{tabular}{|c|c|c|c|c|c|c|c|c|c|}
\hline Line & 1 & 2 & 4 & 5 & 12 & 14 & 15 & 24 & 45 \\
\hline $\begin{array}{l}25^{\circ} \mathrm{C} \text {. } \\
\text { Females } \\
\text { Males }\end{array}$ & $\begin{array}{l}-0.5506 \\
-0.4586\end{array}$ & $\begin{array}{l}0.3288 \\
0.2427\end{array}$ & $\begin{array}{r}0.1809 \\
-0.0294\end{array}$ & $\begin{array}{r}-0.1704 \\
0.4198\end{array}$ & $\begin{array}{l}0.2433 \\
0.1946\end{array}$ & $\begin{array}{l}-0.0424 \\
-0.5803\end{array}$ & $\begin{array}{l}-0.3322 \\
-0.1407\end{array}$ & $\begin{array}{l}0.4494 \\
0.2913\end{array}$ & $\begin{array}{r}-0.1069 \\
0.0605\end{array}$ \\
\hline $\begin{array}{l}18^{\circ} \mathrm{C} . \\
\text { Females } \\
\text { Males }\end{array}$ & $\begin{array}{l}-0.5213 \\
-0.5753\end{array}$ & $\begin{array}{r}-0.0230 \\
0.178 \mathrm{I}\end{array}$ & $\begin{array}{l}0.4786 \\
0.4246\end{array}$ & $\mid \begin{array}{l}-0.1336 \\
-0.1721\end{array}$ & $\begin{array}{r}-0.4790 \\
0.0295\end{array}$ & $\begin{array}{l}0.0830 \\
0.0939\end{array}$ & $\begin{array}{l}0 \cdot 134^{2} \\
0 \cdot 159^{2}\end{array}$ & $\begin{array}{r}0.2667 \\
-0.0428\end{array}$ & $\begin{array}{r}0.1946 \\
-0.0953\end{array}$ \\
\hline $\begin{array}{l}25^{\circ} \mathrm{C} . \\
18^{\circ} \mathrm{C} .\end{array}$ & $\begin{array}{l}-0.5046 \\
-0.54^{83}\end{array}$ & $\begin{array}{l}0.2858 \\
0.0776\end{array}$ & $\begin{array}{l}0.075^{8} \\
0.45^{16}\end{array}$ & $\begin{array}{r}0.1247 \\
-0.1529\end{array}$ & $\begin{array}{r}0.2190 \\
-0.224^{8}\end{array}$ & $\begin{array}{r}-0.3114 \\
0.0885\end{array}$ & $\begin{array}{r}-0.2365 \\
0.1467\end{array}$ & $\begin{array}{l}0.3704 \\
0.1120\end{array}$ & $\begin{array}{r}-0.0232 \\
0.0497\end{array}$ \\
\hline Overall & -0.5265 & 0.1817 & 0.2637 & $-0.014 \mathrm{I}$ & -0.0029 & -0.145 & -0.0449 & $0.24^{12}$ & $0.013^{2}$ \\
\hline
\end{tabular}

so obtained and this average divided by 8 to make the error applicable to the values of table 8 which effectively originate, of course, from the averaging of 8 mixed cultures in table 6 . The value of the pure culture which is also brought into the average is invariable and so this culture is neglected in working out this divisor.

The interactions of lines $\times$ sexes and lines $\times$ sexes $\times$ temperatures in table 8 have very similar mean squares and have therefore been pooled to give a mean square of 0.40 . This is just significant at the I per cent. level when compared with the basic error, suggesting that the relative competitive values between sexes are subject to variation springing from agencies which do not contribute to the basic error. As we have seen, the basic error must be to some extent an underestimate, so that this test of significance cannot be taken wholly at its face value. If, however, agencies of additional variation exist the process of standardisation may be one of them and others may be 
related to sex differences. Be that as it may, however, the interaction of lines and temperatures is significant at the 5 per cent. level even when tested against the pooled sex interactions. Thus there is good reason to believe that the lines do not behave the same with respect to one another at the two temperatures: there is an interaction of genotype and environment in respect of competitive ability. Nor indeed is this surprising, for the conditions of competition could hardly be exactly alike in cultures raised at the two temperatures. The overall differences among the lines is highly significant in this analysis, as would indeed be expected from the analyses set out earlier.

\section{THE INHERITANCE OF COMPETITIVE ABILITY}

The standardised relative competitive values of table 8 have been averaged over sexes for the purpose of considering the contributions of the chromosomes to their determination. These averaged values are set out in relation to the nine genotypes at the two temperatures in table Io. It is not fully justifiable to average over the sexes in

TABLE 9

Analysis of variance of standardised relative competitive abilities

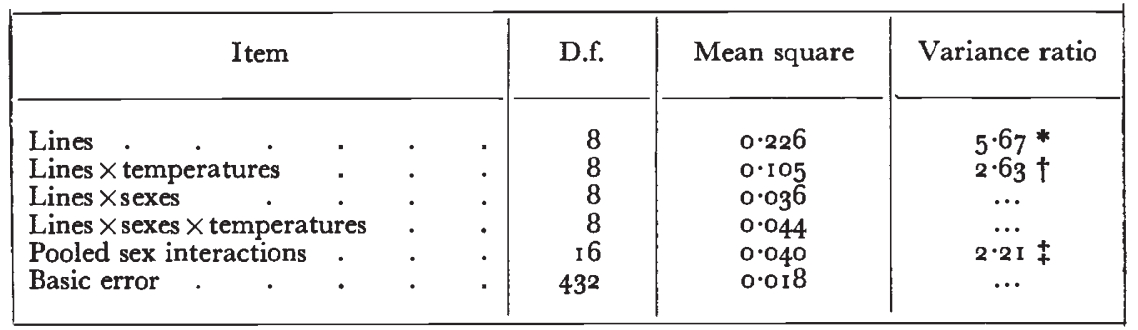

* $\mathbf{P}<\mathrm{I}$ per cent. tested against pooled interactions.

$\dagger \mathbf{P}=5$-Io per cent. tested against pooled interactions.

$\ddagger \mathrm{P}=\mathrm{I}$ per cent. tested àgainst basic error.

respect of effects of the $\mathrm{X}$ chromosomes even though the experimental procedure combines both types of male where variation in the $\mathrm{X}$ is possible. Since, however, the effects of the $\mathrm{X}$ are fully confounded with those of chromosome II, for which averaging over the sexes is clearly legitimate, it was felt that this procedure should not lead to seriously misleading results.

The nine values necessarily sum to o, so that eight parameters are required fully to describe the genetical situation at each temperature. Basically these must of course resemble the two $d$ 's, two $h$ 's, $i$, two $j$ 's and $l$ as defined by Hayman and Mather (1955). In point of fact the structure of the values observed for the individual genotypes is not quite the same as that used by Hayman and Mather, partly because these authors assumed the genotypes to be present with the frequencies appropriate to an $F_{2}$ whereas here they must all be regarded as equally frequent, and partly because Hayman and Mather 
worked from a mean of $\mathrm{S}\left(\frac{1}{2} h\right)$ whereas here we are working from a mean of o. The parameters are, however, essentially the same, even though the operation of reconstructing the genotypic values from them is not quite identical.

The coefficients of the eight orthogonal functions used in deriving estimates of the genetic parameters from the values observed, are set out, together with the divisors appropriate to them, in table II. The

\section{TABLE Io}

\section{The inheritance of competitive ability}

The entries in the table are the standardised relative competitive abilities, averaged over sexes, shown by flies of the genotypes indicated by the margins

\begin{tabular}{|c|c|c|c|c|}
\hline \multicolumn{5}{|c|}{$25^{\circ} \mathrm{C}$. } \\
\hline$+\mathrm{II}$ & $\mathrm{B} / \mathrm{B}$ & $\mathrm{B} / \mathrm{S}$ & $\mathrm{S} / \mathrm{S}$ & Mean \\
\hline $\mathrm{B} / \mathrm{B}$ & -0.505 & 0.219 & 0.286 & 0.000 \\
\hline $\mathrm{B} / \mathrm{S}$ & -0.237 & $-0.31 \mathrm{I}$ & 0.370 & -0.059 \\
\hline $\mathrm{S} / \mathrm{S}$ & 0.125 & -0.023 & 0.076 & 0.059 \\
\hline Mean & -0.205 & -0.038 & 0.244 & 0.000 \\
\hline
\end{tabular}

\begin{tabular}{|c|c|c|c|c|}
\hline \multicolumn{5}{|c|}{$18^{\circ} \mathrm{C}}$. \\
\hline $\mathrm{X}+\mathrm{II}$ & $\mathrm{B} / \mathrm{B}$ & $\mathrm{B} / \mathrm{S}$ & $\mathrm{S} / \mathrm{S}$ & Mean \\
\hline $\begin{array}{l}\mathrm{B} / \mathrm{B} \\
\mathrm{B} / \mathrm{S} \\
\mathrm{S} / \mathrm{S}\end{array}$ & $\begin{array}{r}-0.548 \\
0.147 \\
-0.153\end{array}$ & $\begin{array}{r}-0.225 \\
0.089 \\
0.050\end{array}$ & $\begin{array}{l}0.078 \\
0 \cdot 112 \\
0.452\end{array}$ & $\begin{array}{r}-0.232 \\
0 \cdot 116 \\
0 \cdot 116\end{array}$ \\
\hline Mean & -0.185 & -0.029 & 0.214 & 0.000 \\
\hline
\end{tabular}

bottom two lines of the table show the estimates obtained for the parameters when the coefficients are applied to the values observed for the standardised relative competitive abilities as shown in table 10. The S.S.s taken out by the parameters are of course also obtainable by squaring the values of the functions before applying the divisor. These have been compared with an estimate of error derived from table 9. The pooled error mean square in that table is 0.040 but this must be divided by 2 to make it applicable to the values of table 1o, each of which is itself the average of two measurements of competitive ability, one from males and one from females. Using, therefore, an 
error mean square of 0.020 , the genetic parameters may be tested for significance, and the results of so doing are shown in table II.

The results are suggestive rather than conclusive. There can be no doubt of the additive effect of chromosome III $\left(d_{3}\right)$ on relative competitive ability at both temperatures. Chromosomes $\mathrm{X}$ and II appear to have a similar joint effect $\left(d_{2}\right)$ only at $18^{\circ} \mathrm{C}$., and this may account in major part for the genotype-environment interaction revealed by the analyses of table 9 . No clear direct evidence appears of dominance, though $h_{2}$ is suggestively large at $18^{\circ} \mathrm{C}$. There are,

TABLE II

The genetic parameters of competitive ability

\begin{tabular}{|c|c|c|c|c|c|c|c|c|c|}
\hline \multicolumn{2}{|c|}{$\begin{array}{l}\text { Genotype- } \\
\text { chromosomes }\end{array}$} & \multicolumn{8}{|c|}{ Parameters } \\
\hline $\mathrm{X}+\mathrm{II}$ & III & $d_{2}$ & $h_{2}$ & $d_{3}$ & $h_{3}$ & $i_{2 s}$ & $j_{28}$ & $j_{32}$ & $l_{23}$ \\
\hline $\mathrm{B} / \mathrm{B}$ & $\begin{array}{l}\mathrm{B} / \mathrm{B} \\
\mathrm{B} / \mathrm{S} \\
\mathrm{S} / \mathrm{S}\end{array}$ & $\begin{array}{l}-1 \\
-1 \\
-1\end{array}$ & $\begin{array}{l}-1 \\
-1 \\
-1\end{array}$ & $\begin{array}{r}-1 \\
0 \\
1\end{array}$ & $\begin{array}{r}-1 \\
2 \\
-1\end{array}$ & $\begin{array}{r}1 \\
0 \\
-1\end{array}$ & $\begin{array}{r}1 \\
-2 \\
1\end{array}$ & $\begin{array}{r}1 \\
0 \\
-1\end{array}$ & $\begin{array}{r}1 \\
-2 \\
1\end{array}$ \\
\hline $\mathrm{B} / \mathrm{S}$ & $\begin{array}{l}\mathrm{B} / \mathrm{B} \\
\mathrm{B} / \mathrm{S} \\
\mathrm{S} / \mathrm{S}\end{array}$ & $\begin{array}{l}0 \\
\circ \\
0\end{array}$ & $\begin{array}{l}2 \\
2 \\
2\end{array}$ & $\begin{array}{r}-1 \\
0 \\
1\end{array}$ & $\begin{array}{r}-1 \\
2 \\
-1\end{array}$ & $\begin{array}{l}0 \\
0 \\
0\end{array}$ & $\begin{array}{l}0 \\
0 \\
0\end{array}$ & $\begin{array}{r}-2 \\
0 \\
2\end{array}$ & $\begin{array}{r}-2 \\
4 \\
-2\end{array}$ \\
\hline $\mathrm{S} / \mathrm{S}$ & $\begin{array}{l}\mathrm{B} / \mathrm{B} \\
\mathrm{B} / \mathrm{S} \\
\mathrm{S} / \mathrm{S}\end{array}$ & $\begin{array}{l}\text { I } \\
\text { I } \\
\text { I }\end{array}$ & $\begin{array}{l}-1 \\
-1 \\
-1\end{array}$ & $\begin{array}{r}-1 \\
0 \\
1\end{array}$ & $\begin{array}{r}-1 \\
2 \\
-1\end{array}$ & $\begin{array}{r}-1 \\
0 \\
1\end{array}$ & $\begin{array}{r}-1 \\
2 \\
-1\end{array}$ & $\begin{array}{r}1 \\
0 \\
-1\end{array}$ & $\begin{array}{r}1 \\
-2 \\
1\end{array}$ \\
\hline Divisor & . & 6 & 18 & 6 & 18 & 4 & 12 & 12 & 36 \\
\hline $\begin{array}{c}\text { Observed } \\
25^{\circ} \mathrm{C} . \\
18^{\circ} \mathrm{C} .\end{array}$ & : & $\begin{array}{l}0.030 \\
0.174^{*}\end{array}$ & $\begin{array}{c}-0.030 \\
0.058_{+}^{+}\end{array}$ & $\begin{array}{l}0.225^{*} \\
0.199^{*}\end{array}$ & $\begin{array}{l}-0.019 \\
-0.014\end{array}$ & $\begin{array}{l}-0.210^{*} \\
-0.005\end{array}$ & $\begin{array}{l}-0.075^{\ddagger} \\
-0.018\end{array}$ & $\begin{array}{c}0.039 \\
-0.108 \dagger\end{array}$ & $\begin{array}{l}-0.053 \dagger \\
-0.000\end{array}$ \\
\hline
\end{tabular}

* $\mathrm{P}<0.01 . \quad \dagger \mathrm{P}=0.05-0.01 . \quad \ddagger \mathrm{P}=0.10-0.05$.

however, indications of interaction of all three kinds between the chromosomes, the results at both temperatures being involved. Furthermore, while the only near significant dominance value is positive, all the significant interaction items, and most of the nonsignificant ones, are negative in sign. Such an opposition in sign between dominance and interaction suggests that the latter is of the duplicate gene type, with both dominance and interaction making for high competitive ability as would indeed be expected where selection for the character must be steadily directional towards high ability (Mather, I96o; Breese and Mather, I96I). More and clearer evidence will, however, be required to establish the nature of the genic interactions. 


\section{CONCLUSION}

Unless flies of one genotype can influence the sternopleural chaeta number of those of another through some process of physiological transformation, the evidence for heritable differences among the lines in their relative competitive abilities is strong. Competitive ability as we have measured it must, however, include as components fecundity of the females and hatchability of the eggs as well as ability of the individuals to develop successfully under competitive conditions. Now fecundity and perhaps hatchability should reflect the genotype of the mother rather than that of the offspring. Thus although it would hardly seem likely that fecundity and hatchability are the sole components, their effects cannot be disentangled from those of direct competition in the present results, and they may have introduced complications into the genetical analysis of the immediately foregoing section.

The evidence could clearly be improved and the analysis taken further, in a number of ways. The intensity of competition could be better controlled and the percentage survival determined more accurately by starting the cultures, both pure and mixed, with counted numbers of eggs rather than merely allowing the females to lay such eggs as they would over a constant time. To use varying numbers of eggs would obviously also allow the use and range of validity of the transformation of proportions into normal deviates to be investigated further.

It was thought desirable to establish a case for the occurrence of differences in competitive ability between wild-type lines of flies in the first instance; but the use of only such flies necessarily requires that the calculations of the proportions among the offspring of mixed cultures be based on the comparisons among mean levels of manifestation of continually varying characters. This, as we have seen, brings its own problems in its train, for we may be led to estimate proportions of greater than I and less than o in the mixtures with the consequence that arbitrary corrections must be made when applying the transformation into probits. Furthermore, the innate variability in the manifestation of the character introduces an additional source of error variation into the estimates and prevents, or at least makes difficult, the correct weighting of the probits in subsequent calculations. The use of suitable major genic differences as markers would overcome these difficulties and would now seem appropriate. It would have the further advantage that all the offspring of a mixed culture could be classified, and hence employed in determining the proportions in the offspring of mixed cultures, with less labour even than counting the sternopleural chaetæ of ten individuals of each sex. The error variance should therefore be again reduced by this procedure and more precise analyses and estimates achieved.

With these technical improvements, we may reasonably hope not only to test and refine the method of statistical reduction and measurement and to pursue the genetical analysis further, but also to develop 
the approach so that it can be applied successfully to a wider class of problems.

\section{SUMMARY}

Competition is not synonymous with natural selection but competitive ability must be a major component of fitness in virtually all circumstances. Thus anything that can be learned about it will add correspondingly to our understanding of fitness, its nature and its determination.

Experiments are described designed to test for differences in competitive ability among flies of the nine genotypes derivable from four lines representing all the true-breeding combinations of chromosome III with chromosomes X and II, treated as a unit, from the Oregon and Samarkand lines of Drosophila melanogaster. Crowded mixed cultures were raised at two temperatures from all possible combinations of the nine genotypes taken two at a time, and the proportions of offspring of the two genotypes estimated from the average numbers of sternopleural chaetæ in both sexes. These proportions were transformed into probits for further analysis by statistical techniques devised for the purpose.

Measurements were obtained of the relative competitive abilities of the genotypes in both sexes at $25^{\circ} \mathrm{C}$. and $18^{\circ} \mathrm{C}$. and significant differences were observed among the lines. Results from tests at the two temperatures were not alike. There is evidence of a difference in the intensity of competition in the two environments, and even when allowance is made for this the lines do not appear to stand in the same relationship to one another at the two temperatures in respect of competitive ability.

Analysis of the effects of chromosomes III and chromosomes X and II on relative competitive ability indicate that genic interactions occur among the chromosomes and suggest that these interactions are of the duplicate type to be expected in the determination of a character under directional selection.

Refinements in the experimental technique are considered.

\section{REFERENCES}

BREESE, E. L., AND MATHER, K. I96o. The organisation of polygenic activity within a chromosome in Drosophila. II. Viability. Heredity, I4, 375-399.

COOKE, P., AND MATHER, K. I962. Estimating the components of continuous variation. II. Genetical. Heredity, 17,211 -236.

dobzhansky, тh. 1952. Genetics and the Origin of Species, 3rd edn. Columbia Univ. Press, New York.

Finney, D. J. 1952. Probit Analysis, 2nd edn. Univ. Press, Cambridge.

FISHER, R. A., AND YATES, F. I957. Statistical Tables for Biological, Agricultural and Medical Research, $5^{\text {th }}$ edn. Oliver and Boyd, Edinburgh.

HAYMAN, B. I., AND MATHER, K. I955. The description of genic interactions in continuous variation. Biometrics, $I I, 69-82$.

KNIGHT, G. R., AND ROBERTSON, A. I957. Fitness as a measurable character in Drosophila. Genetics, 42, 524-530. 
MATHER, K. 1949. Biometrical Genetics. Methuen, London.

MATHER, K. 1960. Evolution of polygenic systems. In Evoluzione e Genetica Quaderno 47, pp. 131-152. Acad. Naz. d. Lincei. Rome.

Mather, K. 1961. Competition and cooperation. Symp. Soc. Exp. Biol., 15, 264-281. SAKAI, K. 1961. Competitive ability in plants: its inheritance and some related problems. Symp. Soc. Exp. Biol., 15, 245-263.

WAllace, B., AND vetukhiv, M. 1955. Adaptive organisation of the gene pools of Drosophila populations. Cold Spr. Harb. Symp. Quant. Biol., 20, 303-309.

vetuKhiv, M. 1954. Integration of the genotype in local populations of three species of Drosophila. Evolution, 8, 241-251. 